Check for updates

Cite this: RSC Adv., 2020, 10, 37233

Received 2nd July 2020

Accepted 28th September 2020

DOI: $10.1039 / \mathrm{d}$ Ora05796g

rsc.li/rsc-advances

\section{Flash microwave-assisted solvothermal (FMS) synthesis of photoactive anatase sub-microspheres with hierarchical porosity $\dagger$}

\author{
M. Davide Cappelluti, ${ }^{\text {ab }}$ Emina Hadzifejzovic, ${ }^{c}$ John S. Foord ${ }^{c}$ \\ and Duncan H. Gregory (iD *a
}

The synthesis of nanostructured sub-microspheres of $\mathrm{TiO}_{2}$ anatase with hierarchical nano- and mesoporosity was successfully achieved by using an innovative approach that applies the principles of acidic digestion to microwave (MW) solvothermal synthesis. This process, termed flash microwaveassisted solvothermal (FMS) synthesis, facilitates the formation of spherical particles without surfactants or templating agents, exploiting the rapid reaction kinetics engendered by MW heating. Unlike many other MW-assisted solvothermal methods, the application of constant MW power leads to a rapid increase of the autogenous pressure, inducing burst-nucleation of small primary crystallites and subsequent rapid agglomeration into secondary particles, with reaction times reduced to minutetimescales. The use of non-aqueous polar solvents such as ethanol is key to the production of regular spheres with a narrow size distribution, composed of nanocrystallites. Morphology, porosity, specific surface area, phase composition, crystallite size and optical properties of the particles can be controlled via a judicious selection of physical and chemical synthesis parameters, especially precursor choice and acid concentration. The complex structure of the particles leads to surface areas of up to ca. $500 \mathrm{~m}^{2} \mathrm{~g}^{-1}$ with intergranular mesoporosity. The as-synthesised FMS particles show increased adsorption under dark conditions and selective de-ethylation of rhodamine B under visible light compared to a commercial photocatalyst (Degussa P25). The photodegradation mechanism hinges on the capacity of the spheres to accept electrons from the photoexcited state of molecules at the particle surface, with the large sphere surface area maximising adsorption capacity and improving the efficiency of the photocatalytic processes. The singular characteristics and properties of the particles could pave the way for further applications in water purification and optoelectronic devices.

\section{Introduction}

Titanium dioxide $\left(\mathrm{TiO}_{2}\right)$ is one of the most versatile materials available with everyday essential uses (as a pigment/additive in sunscreen, paints and toothpaste $)^{\mathbf{1 - 3}}$ to very specific technological applications in photocatalysis, water splitting and energy conversion devices such as dye-sensitized solar cells (DSSCs). ${ }^{4}$ Due to its low toxicity and high chemical and thermal stability, $\mathrm{TiO}_{2}$ has gained favour in environmental applications; notably in gas and water purification. ${ }^{5}$

Microspheres produced by the self-assembly of nanoparticles (NPs) are useful mesoporous materials with

\footnotetext{
${ }^{a}$ School of Chemistry, University of Glasgow, University Avenue, Glasgow G12 8QQ, UK.E-mail: Duncan.Gregory@glasgow.ac.uk

${ }^{b}$ School of Engineering, University of Glasgow, Oakfield Avenue, Glasgow G12 8LT, UK ${ }^{c}$ Chemistry Research Laboratory, University of Oxford, Mansfield Road, Oxford OX1 3TA, UK

$\dagger$ Electronic supplementary information (ESI) available. See DOI: 10.1039/d0ra05796g
}

hierarchical superstructures. ${ }^{6}$ Their high porosity and tuneable architectures are important for catalysis and sensing applications and increasingly for DSSCs. ${ }^{7}$ Such microspheres are also promising in energy storage and can serve as electrodes for $\mathrm{Li}$ ion batteries. ${ }^{8,9}$ Further, hierarchical $\mathrm{TiO}_{2}$ microparticles have a future in environmental technologies such as water treatment and purification via photo-enhanced mineralisation of organic matter and microorganisms. ${ }^{\mathbf{1 0}}$ Highly photoactive-high surface area mesoporous $\mathrm{TiO}_{2}$ microparticles have the potential to replace titania NPs, allaying issues such as the dispersibility and toxicity of semiconductor NPs in the colloidal state. ${ }^{11-13}$ Mesoporous $\mathrm{TiO}_{2}$ microparticles can be simply separated from water and the catalyst recovered under gravity, without causing secondary pollution. ${ }^{13}$

Often the main challenge in the use of micron-scale particles is to prevent reduction of surface area and, for example, a corresponding loss of photocatalytic efficiency. One approach is to nanostructure the particles hierarchically, introducing porosity across length scales. Mesopores increase not only the specific surface area but also the density of reactive sites, which are 
fundamental for photocatalytic applications. Indeed, an improvement of photoactivity can also be achieved in the presence of macropores, which provide a light-transfer path for the distribution of photon energy. ${ }^{\mathbf{1 4}}$

Among methods for the production of $\mathrm{TiO}_{2}$ NPs and mesoporous microparticles, solvothermal synthesis yields high purity and crystallinity, both of which are essential in optical and electronic applications. Porosity can be modified in such materials by tempering the reactivity of the Ti(Iv) precursor or by employing stabilizing or templating agents such as surfactants and co-polymers. ${ }^{15,16}$ Meanwhile, replacing conventional heat sources in solvothermal reactions with microwaves (MWs) dramatically enhances the reaction kinetics. This can reduce synthesis procedures to one step and can overcome the main limitations of hydrothermal processes by cutting durations from many hours (or days) to minutes. ${ }^{17} \mathrm{MW}$-assisted routes now exist for the synthesis of many inorganic nanomaterials, including $\mathrm{TiO}_{2}$ NPs. ${ }^{18-21}$ However, to produce self-assembled, hierarchical structures such as mesoporous microspheres, requires more complicated procedures, typically employing templating agents. ${ }^{22,23}$

In this paper, we propose a "Flash Microwave Solvothermal (FMS)" route to synthesise spherical mesoporous microspheres. The concept of flash chemistry was introduced relatively recently in the wider literature to describe highly controlled reactions performed in minute-, or even second-timescales, ${ }^{\mathbf{2 4 - 2 6}}$ whereas the term "flash" was associated in the past with rapid materials syntheses such as MW-assisted or-induced processes. ${ }^{20,27-29}$ The flash process herein, however, concerns acidic digestion under MW irradiation, by analogy to methods used in analytical techniques such as elemental trace analysis via ICP. ${ }^{30} \mathrm{MW}$ irradiation facilitates the extremely rapid heating of polar solvents in closed systems to temperatures above their boiling points, due to the increase of the autogenous pressure during the heating process. ${ }^{31}$ This can lead to 1000 -fold acceleration of reaction rate when using ethanol in a closed MW system, for example. ${ }^{32}$ Acids in solution further contribute to pressure rises in closed systems via decomposition processes. ${ }^{33,34}$ Indeed, combining non-aqueous solvents with acidic anions has proved key in the formation of microspheres in such MW syntheses without the need of templating agents. $^{35-37}$

Commercial MW reactors equipped with pressure sensors and capable of controlling the reaction temperature through incident MW power have been successfully employed for MW solvothermal synthesis. ${ }^{31,37-39}$ FMS synthesis differs from this approach, applying constant MW power and exploiting the variation in pressure as the reaction proceeds. ${ }^{40}$

To the best of our knowledge, there are no systematic studies reported for the synthesis of nanostructured sub-micron titania using second-scale MW-assisted solvothermal synthesis, mainly due to the difficulties in controlling the reaction parameters and in observing how these affect the resulting products. Not only were we intrigued to compare the FMS materials to other $\mathrm{TiO}_{2}$ in terms of structure and composition, but also we were interested to investigate how certain physical and chemical properties might be influenced by the preparation method and ensuing hierarchical mesoporous structure. Therefore we measured a number of physical properties and focused on photocatalysis as a key chemical property of $\mathrm{TiO}_{2}$. The FMS materials were compared both with commercially available $\mathrm{TiO}_{2}$ catalysts (Degussa P25) and with lab-scale $\mathrm{TiO}_{2}$ microspheres synthesied by established conventional routes. ${ }^{37,38}$ The photodegradation of rhodamine $\mathrm{B}(\mathrm{RhB})$ was used as benchmark test for the qualification of the $\mathrm{FMS}^{-\mathrm{TiO}_{2}}$ microsphere photocatalytic properties, making use of the rich and detailed literature available describing $\mathrm{RhB}$ degradation in the presence of $\mathrm{TiO}_{2}$ materials. ${ }^{\mathbf{4 1}, \mathbf{4 2}}$

\section{Experimental methods}

\section{Microwave-assisted flash hydrothermal synthesis}

All chemicals were used as received without further purification. Titanium tetraisopropoxide (TTIP, Sigma-Aldrich, >97\%) was added dropwise to an acidic solution in an ice-bath to prevent the fast hydrolysis reaction of the alkoxide. The acid, $\mathrm{HNO}_{3}$ (Fluka, 70\% v/v), was used as a means to control the growth and nucleation process in a series of experiments with a concentration varied from 0.5 to $2 \mathrm{M}$ while varying the concentration of the added alkoxide (20 to $640 \mathrm{mM}$ ). Either deionised water (Millipore Q-water, $18 \mathrm{M} \Omega$ ) or absolute ethanol (VWR) were used as solvents. After 30 minutes of continuous stirring, the precursor solution was poured into a $45 \mathrm{~mL}$ doublewalled autoclave vessel consisting of an inner Teflon container and an outer shell of high strength MW-transparent polymer (MW digestion bomb, Anton-Paar, US). The autoclave was placed into a multimode cavity (MMC) MW reactor (Sharp R272, $800 \mathrm{~W}$ ). MW irradiation at $800 \mathrm{~W}, 2.45 \mathrm{GHz}$ was applied for times between 15-180 s. For most synthesis experiments, the irradiation time was set to $60 \mathrm{~s}$.

The resulting cloudy colloidal suspension was centrifuged and washed with de-ionized water and absolute ethanol to separate the precipitate from the acid solution. The precipitate was dried at $60{ }^{\circ} \mathrm{C}$ for $2 \mathrm{~h}$ to obtain a very fine powder. All samples were sealed and stored in a desiccator to prevent moisture ingress. Selected samples were subsequently calcined at different temperatures $\left(300-600{ }^{\circ} \mathrm{C}\right.$ ) for $3 \mathrm{~h}$ in air for comparison with as-synthesised materials.

\section{Characterisation techniques}

Scanning Electron Microscopy (SEM) was performed with a Philips/FEI XL30 ESEM (20 kV, maximum magnification 20k) equipped with an INCA X-Act detector (Oxford Instruments Analytical, UK) for energy dispersive X-ray spectroscopy (EDS). High-resolution SEM images were collected using a Carl Zeiss Sigma Variable Pressure Analytical SEM (resolution of $2.8 \mathrm{~nm}$ / $1.5 \mathrm{~nm}$ at $1 \mathrm{kV} / 15 \mathrm{kV}$ ) fitted with a Oxford Microanalysis detector. The particle size distribution was estimated by measuring the diameter of hundreds of particles across multiple data sets by using the Image software package (a typical procedure shown in Fig. S1 $\dagger$ ). ${ }^{43}$ TEM images and SAED analysis were performed by using a FEI Tecnai TF20 microscope (spherical aberration coefficient of $1.2 \mathrm{~mm}$, with 2.4 point 
resolution and 1.5 line resolution). The instrument was also used to perform high angle annular dark field (HAADF) measurements. X-ray photoelectron spectroscopy (XPS) was performed using a VGX900-Escalab instrument $(\mathrm{K} \alpha \mathrm{Al}, E=$ $1486.6 \mathrm{eV}$, operating pressure $1 \times 10^{-6} \mathrm{~Pa}$ ). Depth profile XPS analysis by argon sputtering was performed on selected samples. All XPS spectra were analysed using XPS Casa software. Nitrogen, carbon and hydrogen content was estimated by combustion analysis with a CE440 elemental analyser (Exeter Analytics, UK).

Powder X-ray diffraction (PXD) was performed with a PANalytical X'Pert Pro MPD diffractometer $(\mathrm{Cu} \mathrm{K} \alpha$ radiation, $\lambda=$ $1.5406 \AA$; accelerating voltage and emission current of $40 \mathrm{kV}$ and $40 \mathrm{~mA}$, respectively). PXD patterns were collected at room temperature for $15 \leq 2 \theta \leq 85^{\circ}$ with a step size of $0.0167^{\circ} \mathrm{s}^{-1}$. Microstructural characterisation from PXD data was performed by whole powder pattern modelling (WPPM) using PM2K software. $^{44,45}$ IR spectra were collected at room temperature (50 scans/sample, $8 \mathrm{~cm}^{-1}$ resolution) using a Shimadzu FTIR $8400 \mathrm{~S}$ spectrometer with a Pike MIRacle ATR sampling accessory. Raman spectroscopy was performed by using a Horiba-Jobin Ivon LabRAM HR confocal microscope (Horiba Ltd., Kyoto, Japan) system with a variable optical hole aperture (100-300 $\mu \mathrm{m}) 600 \mathrm{~mm}^{-1}$ grating and a Synapse CCD detector. The excitation source was a Nd:YAG second harmonic laser (Ventus532, Laser Quantum, emission $\lambda=532 \mathrm{~nm}$, output power $50 \mathrm{~mW}$ to $1.5 \mathrm{~W})$. The spectra were collected over an effective Raman shift range of $10-1000 \mathrm{~cm}^{-1}$. Laser intensity was tuned from 1 to $25 \%$ of the maximum power, preventing in situ modification (heating) of the samples (e.g. phase transformations). Dynamic Light Scattering (DLS) was performed with a Malvern Zetasizer instrument.

The optical band-gaps of samples was determined using diffuse reflectance UV-Vis (DR-UV-Vis) spectroscopy (Shimadzu UV-2700 equipped with an integrating sphere; ISR-2600 Plus, Shimadzu, Japan). BaSO $_{4}$ (Nacalai Tesque, Japan) was used as a reference for both absorbance and reflectance measurements. The spectra were recorded at room temperature in a wavelength range of 190-1300 $\mathrm{nm}$.

Simultaneous thermogravimetric-differential thermal analysis (TG-DTA) was performed with a Netzsch STA 409 PC (Germany) instrument. Mass spectrometry (MS) of the evolved gases during the thermal analysis was performed with a Hiden Analytical HPR 20 instrument, equipped with a quadrupole mass analyser. Nitrogen physisorption experiments for determination of specific surface area and pore analysis were performed using a Quantachrome EVO analyser.

\section{Photodegradation tests}

Rhodamine $\mathrm{B}$ (RhB, $\mathrm{C}_{28} \mathrm{H}_{31} \mathrm{~N}_{2} \mathrm{O}_{3} \mathrm{Cl}$, CAS: 81-88-9, $\mathrm{MW}=$ $479.02 \mathrm{~g} \mathrm{~mol}^{-1}, \lambda_{\max }=553 \mathrm{~nm}$, Sigma-Aldrich, $\geq 95 \%$ ) was used without further purification as a test molecule for photocatalytic measurements. Powdered $\mathrm{TiO}_{2}$ samples were mixed with RhB solution $\left(1.5 \times 10^{-5} \mathrm{M}\right)$ to give suspensions of catalyst concentration from $100 \mathrm{mg} \mathrm{L}^{-1}$ to $1 \mathrm{~g} \mathrm{~L}^{-1}$, which were sonicated for $10 \mathrm{~min}$ to improve the particle dispersion. Each suspension was stirred under dark conditions for at least $30 \mathrm{~min}$ to achieve the adsorption-desorption equilibrium of RhB on the particle surfaces. Each suspension was irradiated with different sources of light, under continuous stirring. The temperature was monitored and maintained at $20{ }^{\circ} \mathrm{C}$. The dye concentration was measured via UV-Vis absorption spectroscopy (Shimadzu UV 2600 spectrophotometer). The photocatalytic activities of commercial anatase and $\mathrm{TiO}_{2}$-based photocatalysts (Aeroxide ${ }^{\circledR}$ P25, Evonik, Germany and KronoClean 7000, Kronos, Germany) were measured following the same procedure for comparison.

\section{Experimental results}

\section{Structural analysis}

Typical PXD patterns of as-synthesised $\mathrm{FMS}^{-\mathrm{TiO}_{2}}$ samples before and after calcination at different temperatures are presented in Fig. 1. The as-synthesised particles (pattern a) show a low degree of crystallinity, with broad peaks typical for nanosized crystallites attributable to anatase $\mathrm{TiO}_{2}$ (ICDD PDF no. 211272). From the appearance of the pattern, amorphous domains cannot be excluded and at least $5 \%$ of a sample would be expected to contain crystalline domains for Bragg peaks to be discernible by PXD. ${ }^{46}$ Estimations of the crystallite size of the assynthesised powder by employing either the Scherrer equation or the WPPM method gave diameters of $c a$. 3-5 nm (results available in Fig. S2, S3 and Table S1, ESI $\dagger$ ). These results are comparable with previous data on $\mathrm{TiO}_{2}$ prepared by hydrolysis of $\mathrm{TiCl}_{4}$ at $-20^{\circ} \mathrm{C}$, which gave qualitatively similar PXD patterns from samples that were $c a$. 70-80\% amorphous containing NPs 2-4 nm in diameter. ${ }^{47}$ Calcining the $\mathrm{FMS}^{-\mathrm{TiO}_{2}}$ led to narrower peaks in the PXD patterns and evidently improved the sample crystallinity. The phase transition from anatase to rutile occurred in the range $500-700{ }^{\circ} \mathrm{C}$, with the transition temperature depending on the specific synthesis conditions employed. The estimation of crystallite size at each calcining temperature is reported in Table 1 . After calcination at $300{ }^{\circ} \mathrm{C}$, the size of the

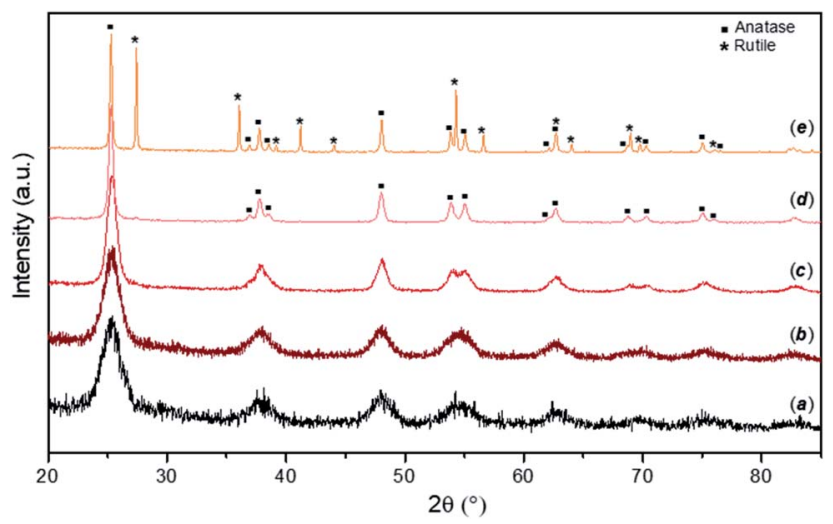

Fig. 1 PXD patterns for as-made FMS samples (2 $\mathrm{M} \mathrm{HNO}_{3} / 160 \mathrm{mM}$ TTIP; 1 min MW treatment) calcined for $3 \mathrm{~h}$ in air at different temperatures showing: (a) as-prepared sample; samples after heating to: (b) $300{ }^{\circ} \mathrm{C}$, (c) $400{ }^{\circ} \mathrm{C}$, (d) $500{ }^{\circ} \mathrm{C}$ and (e) $600{ }^{\circ} \mathrm{C}$ respectively. Anatase (squares) and rutile (asterisks) reflections are indicated on the patterns for samples heated at $500{ }^{\circ} \mathrm{C}$ and $600^{\circ} \mathrm{C}$ respectively. 
Table 1 Crystallite size (diameter), principal Raman bands and experimental indirect band gaps for selected FMS TiO $\mathrm{Fub}_{2}$-microsphere samples ( $2 \mathrm{M} \mathrm{HNO}_{3}, 160 \mathrm{mM} \mathrm{TTIP}, 1$ min MW treatment) before and after calcination at the indicated temperaures. Bands marked with "** indicate where Anatase and Rutile Raman peaks overlap

\begin{tabular}{|c|c|c|c|c|c|c|c|}
\hline & \multirow{2}{*}{$\begin{array}{l}\text { PXD } \\
\text { Crystallite size }^{a} / \mathrm{nm}\end{array}$} & \multicolumn{5}{|l|}{ Raman } & \multirow{2}{*}{$\begin{array}{l}\text { DR-UV-Vis } \\
\text { Band gap } c / e V\end{array}$} \\
\hline & & \multicolumn{2}{|l|}{$\mathrm{E}_{\mathrm{g}, \mathrm{I}} \operatorname{mode}^{b}$} & $\frac{\mathrm{A}_{1 \mathrm{~g}} \operatorname{mode}^{b}}{\operatorname{Max} / \mathrm{cm}^{-1}}$ & $\frac{\mathrm{B}_{1 \mathrm{~g}} \operatorname{mode}^{b}}{\mathrm{Max} / \mathrm{cm}^{-1}}$ & $\frac{\mathrm{E}_{\mathrm{g}, \mathrm{III}} \operatorname{mode}^{b}}{\operatorname{Max} / \mathrm{cm}^{-1}}$ & \\
\hline Untreated & 4.3 & 147.9 & 22.9 & 392.7 & 514.4 & 640.0 & 3.38 \\
\hline $300{ }^{\circ} \mathrm{C}$ & 5.1 & 147.0 & 19.7 & 398.0 & 516.2 & 641.7 & 3.32 \\
\hline $600^{\circ} \mathrm{C}$ & 38.4 & 142.8 & 10.4 & $399.0^{*}$ & $516.8^{*}$ & $627.3^{*}$ & 3.03 \\
\hline
\end{tabular}

crystallites remains close to that of the untreated particles $(<10$ $\mathrm{nm})$. Thereafter, the crystal size increases almost linearly between $400{ }^{\circ} \mathrm{C}$ and the phase transition temperature, at which point the anatase grains are progressively converted into rutile, slowing the crystal growth rate (Fig. S4, ESI $\dagger$ ).

\section{Morphology, size distribution and internal structure}

A distinctive characteristic of the FMS synthesis is the formation of spherical particles, which become more uniform as they increase in size. The morphology of the sub-microspheres was investigated by SEM analysis (Fig. 2a and b). Both the average diameter and the size distribution of the spheres depends on the synthesis conditions, with the former varying from $c a$. $100 \mathrm{~nm}$ to $1-2 \mu \mathrm{m}$. Formation of the spherical particles was not observed when an $\mathrm{HNO}_{3}$ concentration below $0.5 \mathrm{M}$ was used. Higher resolution imaging confirmed the smoothness of the particle surface (Fig. 2c and d). A size distribution analysis was performed across a tranche of SEM images for each sample and (a)

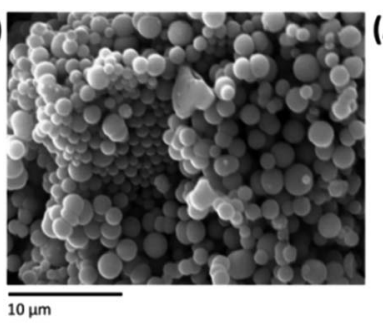

(c)

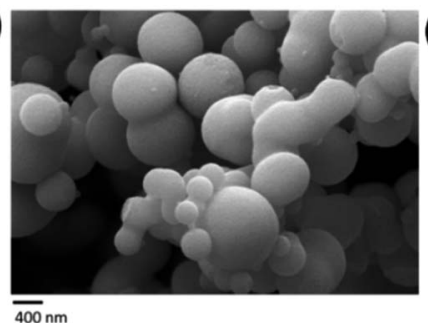

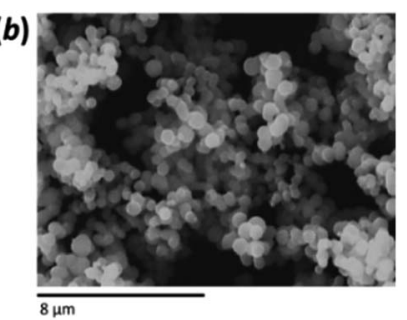

(d)

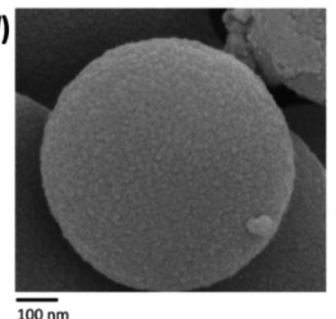

Fig. 2 SEM images showing examples of as-made $\mathrm{FMS} \mathrm{TiO}_{2}$ submicrospheres using ethanol as a solvent with: (a) $0.5 \mathrm{M} \mathrm{HNO}_{3} / 320 \mathrm{mM}$ TTIP; (b) $1 \mathrm{M} \mathrm{HNO}_{3}$,/80 mM TTIP. (c and d) HR-SEM images of FMS$\mathrm{TiO}_{2}$ sub-microspheres produced using $1 \mathrm{M} \mathrm{HNO}_{3}, 160 \mathrm{mM}$ TTIP. the spheres are relatively monodisperse under most synthesis conditions (with an average relative standard deviation of $c a$. $25 \%$ ). The mean sphere diameter is, however, strongly influenced by the synthesis conditions (ESI, Fig. S5 $\dagger$ ) and overall the sphere size increased with the amount of precursor and the decrease of the acid concentration; the latter effect being the more dramatic. Higher acid concentrations also tended to narrow the size distribution, whereas using the minimum concentration necessary to produce spheres generated broad or multimodal distributions (ESI, Fig. S6a $\uparrow$ ). The influence of the precursor was greater at lower acidity and a clear trend is shown when using $1 \mathrm{M} \mathrm{HNO}_{3}$ (ESI, Fig. S6b†). Finally, the morphology of the spheres was not affected by the calcination process (SEM distribution reported in Table S3, ESI; $\uparrow$ see also below).

The agglomeration behaviour of the microparticles in water was tested by measuring the hydrodynamic diameter via DLS. (ESI Fig. S6 $\dagger$ ). Multiple DLS measurements were performed on the $2 \mathrm{M} \mathrm{HNO}_{3} / 80 \mathrm{mM}$ TTIP and $1 \mathrm{M} \mathrm{HNO}_{3} / 160 \mathrm{mM}$ TTIP samples that had been analysed in the solid state using SEM. In both cases the maxima of the DLS size distributions were in good agreement with those obtained from SEM image data. Two clear distinctions could be made when comparing the solution state and solid state size distributions, however: first, DLS did not reproduce the bimodal distribution seen by SEM for the $2 \mathrm{M}$ $\mathrm{HNO}_{3} / 80 \mathrm{mM}$ TTIP sample, giving rather a broad monomodal distribution in solution (ESI Fig. S6at); second although the SEM and DLS distribution profiles were similar for the $1 \mathrm{M}$ $\mathrm{HNO}_{3} / 160 \mathrm{mM}$ TTIP sample, the latter yielded a broader distribution with a somewhat higher average particle size in solution (Fig. S6b†). Nevertheless, importantly, the DLS measurements demonstrated that good dispersions of the submicrospheres in aqueous media could be achieved, with no evidence of aggregation to form larger clusters.

Further information about the intricate internal structure of the samples was gleaned from TEM analysis. Entire spheres were too thick for the electron beam to pass through them (Fig. 3a and ESI, Fig. S7a and b†). However, smaller crystallites are observable at the outer surface/edges of the spheres (Fig. 3b). Although the TEM image resolution did not allow a quantitative determination of the size of these crystallites, the 


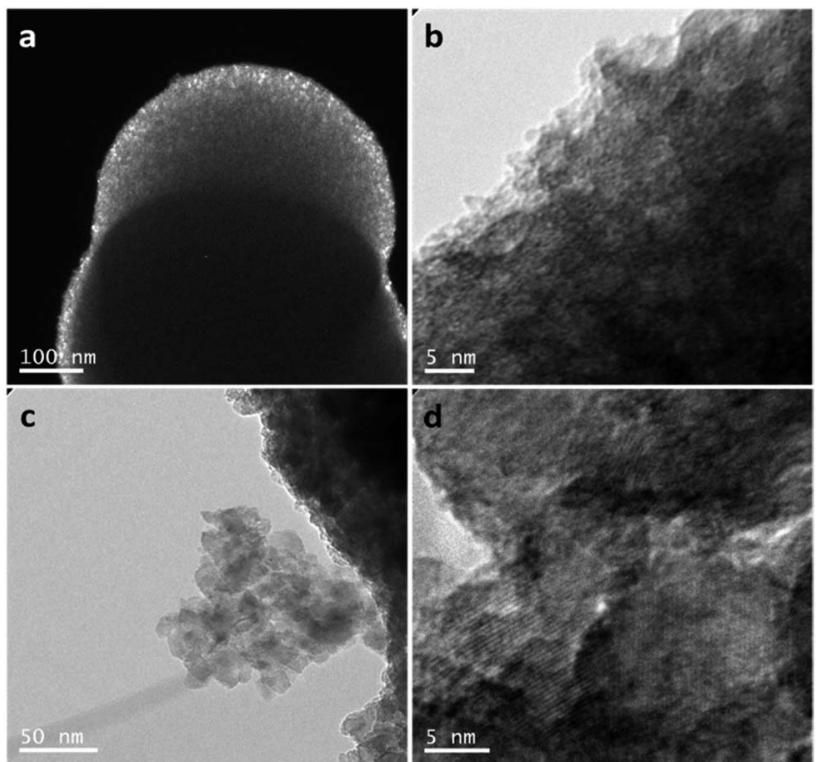

Fig. 3 TEM images of as-made $F M S-\mathrm{TiO}_{2}$ sub-microspheres synthesised in absolute ethanol with $2 \mathrm{M} \mathrm{HNO}_{3}, / 160$ mM TTIP: (a) dark field image of the spheres; (b) bright field image showing the detail of the sphere surface at high magnification; (c) cluster of primary NPs dissociated from a sub-microsphere after calcination at $500^{\circ} \mathrm{C}$ for $3 \mathrm{~h}$ $\left(10{ }^{\circ} \mathrm{C} \mathrm{min}^{-1}\right)$ and (d) detail of the lattice fringes observable at high magnification after calcination at $500{ }^{\circ} \mathrm{C}$ for $3 \mathrm{~h}\left(10{ }^{\circ} \mathrm{C} \mathrm{min}^{-1}\right)$.

component particles are evidently 3-4 orders of magnitude smaller than the spheres themselves and likely within the size regime determined by the analysis of the PXD data. Clear diffraction fringes are not detectable from these very small particles, also supporting observations from our analysis of the PXD patterns. However, HAADF imaging clearly revealed the presence of the small crystallites, which could be identified by the bright contrast spots at different diffraction angles (ESI, Fig. S8 ${ }^{4} .^{48}$ The calcination process tends to cause the growth of the component nanocrystallites (Fig. 3c) without altering the spherical shape of the secondary particles (ESI, Fig. S7c and S9†). The crystallites in the calcined samples are apparently randomly oriented and the anatase (101) planes are easily discernible (Fig. 3d). Selected area electron diffraction (SAED) was also performed on a representative $\mathrm{TiO}_{2}$ sample $\left(2 \mathrm{M} \mathrm{HNO}_{3} /\right.$ $160 \mathrm{mM}$ TTIP; $1 \mathrm{~min}$ MW treatment) before and after calcination at $500{ }^{\circ} \mathrm{C}$. Before calcination, the small primary particles gave patterns containing diffuse powder rings (whereas for a completely amorphous material such discrete rings associated with a family of planes degenerate into a circular halo ${ }^{49}$ ). The most intense rings could be indexed to the same reflections observed in the PXD patterns. After thermal treatment, the SAED patterns evolved from rings to spots indicating the growth of the particles and increase in crystallinity (ESI, Fig. S10 $\dagger$ ).

\section{Raman spectroscopy}

The Raman bands of the $\mathrm{FMS}-\mathrm{TiO}_{2}$ particles correspond to those reported for anatase (spectra are shown as a function of acid and precursor concentration in Fig. 4 and 5, respectively).

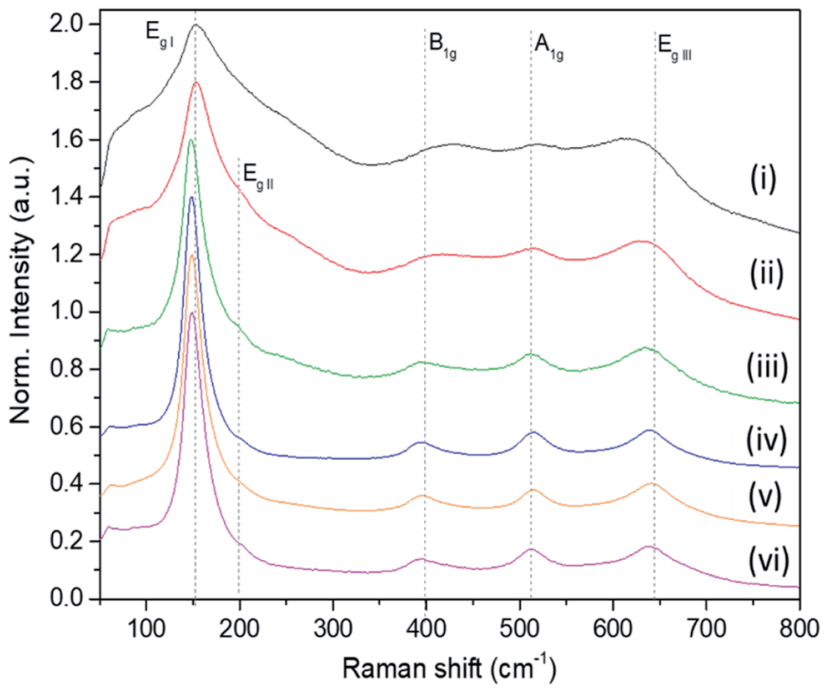

Fig. 4 Raman spectra of as-made $\mathrm{FMS} \mathrm{TiO}_{2}$ sub-microspheres ( $1 \mathrm{M}$ $\mathrm{HNO}_{3}$ ) as a function of the TTIP concentration, using: (i) $20 \mathrm{mM}$, (ii) $40 \mathrm{mM}$, (iii) $80 \mathrm{mM}$, (vi) $160 \mathrm{mM}$, (v) $320 \mathrm{mM}$ and (vi) $650 \mathrm{mM}$ TTIP, respectively. The spectra are normalised against the $E_{g, l}$ mode peak intensity.

Factor group analysis indicates the existence of 6 Raman active optical modes for the space group $\left(D_{4 \mathrm{~h}}{ }^{19} ; I 4_{1} / \mathrm{amd}\right)$ adopted by anatase: $\mathrm{E}_{\mathrm{g}, \mathrm{I}}\left(143 \mathrm{~cm}^{-1}\right), \mathrm{E}_{\mathrm{g}, \mathrm{II}}\left(197 \mathrm{~cm}^{-1}\right), \mathrm{B}_{1 \mathrm{~g}}\left(399 \mathrm{~cm}^{-1}\right), \mathrm{A}_{1 \mathrm{~g}}$ $\left(513 \mathrm{~cm}^{-1}\right), \mathrm{B}_{1 \mathrm{~g}}(2)\left(519 \mathrm{~cm}^{-1}\right.$, overlapping with $\left.\mathrm{A}_{1 \mathrm{~g}}\right)$ and $\mathrm{E}_{\mathrm{g}, \mathrm{III}}$ $\left(639 \mathrm{~cm}^{-.1}\right) . .^{50}$ The definition of the bands is affected by the poor crystallinity of the samples, with absolute intensity comparable to the stray light shoulder (generally occurring before $100 \mathrm{~cm}^{-1}$ ). The $E_{g, I}$ band was shifted to a lower frequency compared to that reported for anatase (Table 1). The full-width at half-maximum (FWHM) of this band is also large, such that it overshadows the $E_{g, I I}$ mode. Peak red-shift and broadening can be linked to the presence of nanocrystals, both effects

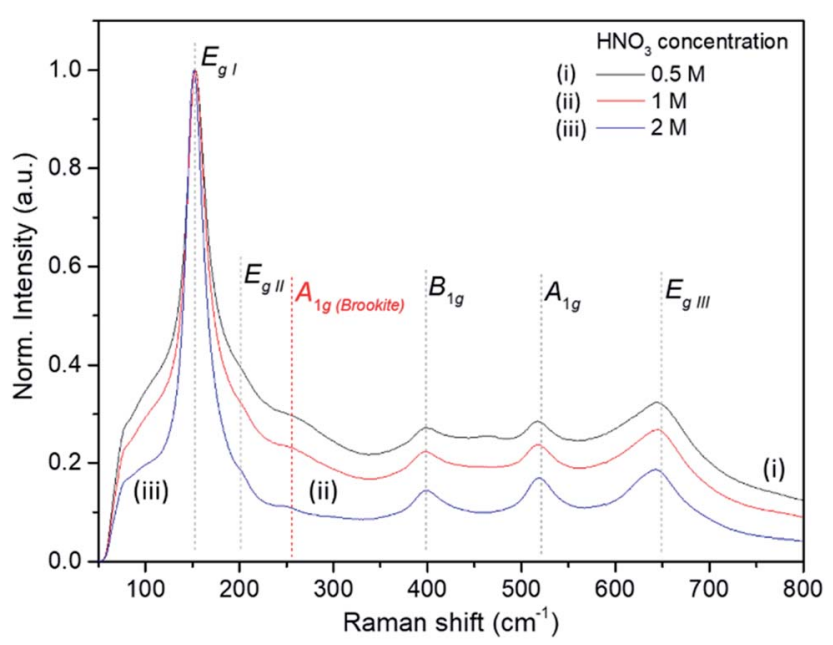

Fig. 5 Raman spectra of selected as-made $\mathrm{FMS} \mathrm{TiO}_{2}$ sub-microspheres ( $80 \mathrm{mM}$ TTIP) as a function of acid concentration, using: (i) $0.5 \mathrm{M}$, (ii) $1 \mathrm{M}$ and (iii) $2 \mathrm{M} \mathrm{HNO}_{3}$ respectively. The spectra are normalised against the $E_{g, l}$ mode peak intensity. 
increasing with the decrease of the crystallite size (ESI, Fig. S11 $\dagger$ ). For very small particles, the quantum size effect leads to the breaking of the rule of phonon momentum conservation for Raman scattering, allowing all phonons present in the Brillouin zone to contribute. The Raman bands are affected by this phonon dispersion, causing broadening and peak shift. ${ }^{\text {1,52 }}$

Raman spectroscopy further evidences the influence of the synthesis parameters. For example, Fig. 4 shows that increasing the precursor concentration improves the crystallinity of the final particles, with Raman bands demonstrating a reduced shift and less broadening. A similar effect is observed as the acid concentration is increased (Fig. 5; ESI Table S2†). A very small peak at $c a .250 \mathrm{~cm}^{-1}$ can be observed in less crystalline samples. This peak might be attributed to the $A_{1 g(4)}$ mode of brookite, which occurs at $246 \mathrm{~cm}^{-1}$ and is one of the few bands that do not overlap with anatase modes (ESI, Fig. S12 $\dagger$ ). ${ }^{53}$ It is conceivable that a low phase fraction of nanocrystalline brookite could be present in FMS samples given the presence of a very weak and broad signal in the $30 \leq 2 \theta \leq 35^{\circ}$ region of the PXD patterns, which could correspond to the most intense (121) peak of brookite $\left(2 \theta=30.83^{\circ}\right.$ for $\mathrm{Cu} \mathrm{K} \alpha$ radiation $) . .^{54}$

\section{Surface area and pore size distribution}

The as-synthesised FMS $\mathrm{TiO}_{2}$ sub-microparticles possess a very high specific surface area. Fig. 6a shows adsorption-desorption isotherms of $\mathrm{TiO}_{2}$ particles synthesised using $1 \mathrm{M}$ and $2 \mathrm{M}$ $\mathrm{HNO}_{3}$ and different precursor concentrations. BET analysis of the isotherm data of some representative samples gave values from $c a .50-500 \mathrm{~m}^{2} \mathrm{~g}^{-1}$ depending on the synthesis conditions (ESI, Table $\mathrm{S} 3 \dagger$ ). An increase in acidity leads to a transformation of the isotherms from type II to type IV according to the IUPAC classification. The hysteresis profile of type IV isotherms is characteristic of the presence of mesopores. ${ }^{55}$ The shape of these curves indicates the presence of pore blocking, typical of a mesoporous network with a large size distribution of pore neck width (H2(b) hysteresis loop) and the same hysteresis has been observed in mesoporous ordered silica materials after hydrothermal treatment. ${ }^{56}$ A classical estimation of the pore size distribution for the $2 \mathrm{M} \mathrm{HNO}_{3}$ samples using the $\mathrm{BJH}$ method gave a pore size distribution centred at a radius of $c a$. $2 \mathrm{~nm}$, the lower edge of the mesopore region in the conventional classification (Fig. 6b) However, DFT analysis revealed a more complex pore network composed of micropores with radii of $c a .1 \mathrm{~nm}$, larger cavities with radii between $1.5-2.4 \mathrm{~nm}$
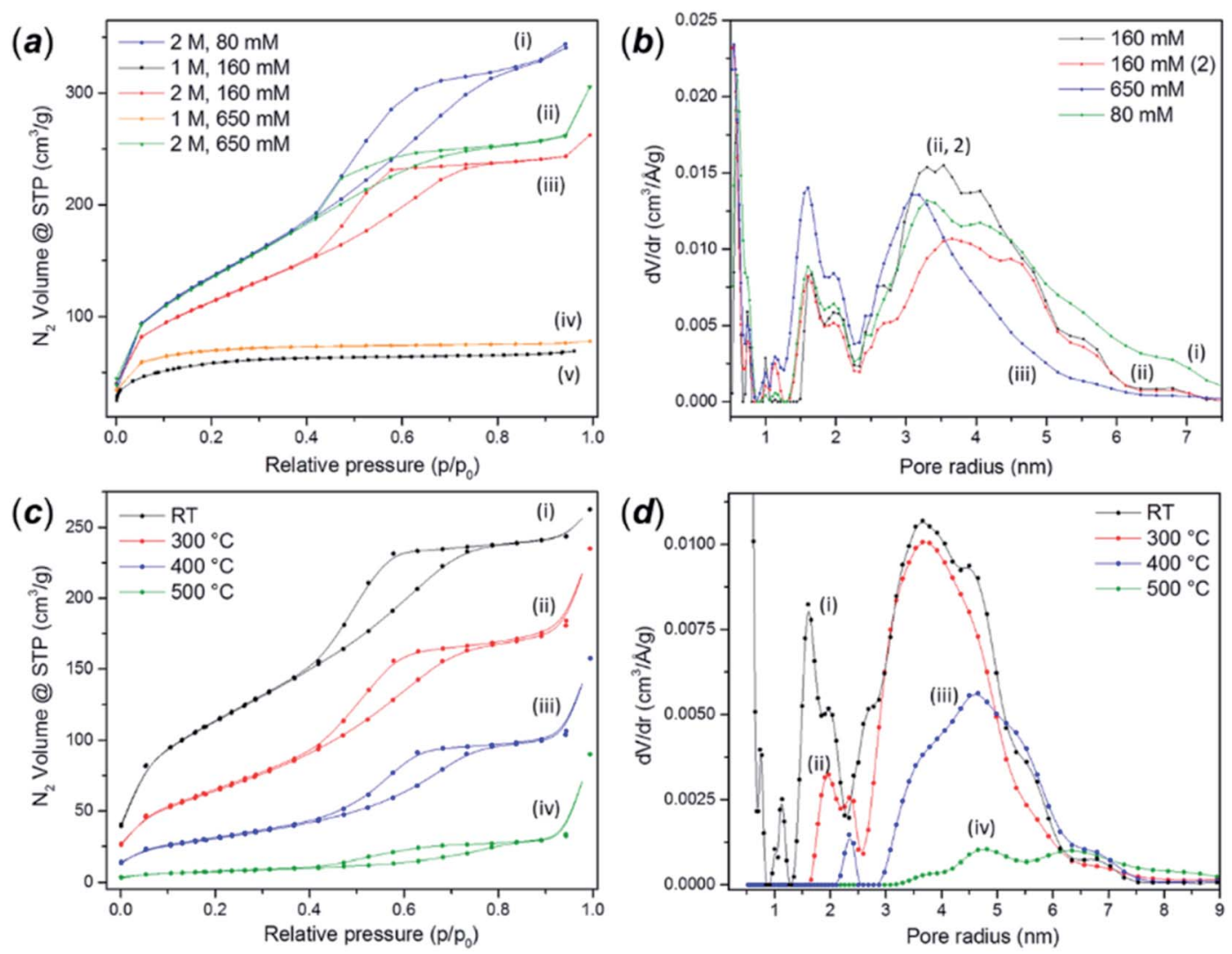

Fig. 6 (a) Nitrogen adsorption-desorption isotherms of as-made $\mathrm{FMS} \mathrm{TiO}_{2}$ sub-microspheres prepared using different concentrations of $\mathrm{HNO}_{3}$ and alkoxide precursor respectively: (i) $2 \mathrm{M} \mathrm{HNO}_{3} / 80 \mathrm{mM}$ TTIP, (ii) $1 \mathrm{M} \mathrm{HNO}_{3} / 160 \mathrm{mM}$ TTIP, (iii) $2 \mathrm{M} \mathrm{HNO}_{3} / 160 \mathrm{mM} \mathrm{TTIP}$, (iv) $1 \mathrm{M} \mathrm{HNO} / 650 \mathrm{mM}$ TTIP and (v) $2 \mathrm{M} \mathrm{HNO}_{3} / 650 \mathrm{mM} \mathrm{TTIP;} \mathrm{(b)} \mathrm{QS-DFT} \mathrm{calculation} \mathrm{of} \mathrm{the} \mathrm{pore} \mathrm{size} \mathrm{distribution} \mathrm{performed} \mathrm{on} \mathrm{the} \mathrm{adsorption} \mathrm{branch} \mathrm{of} \mathrm{selected} \mathrm{FMS}$ $\mathrm{TIO}_{2}$ sub-microsphere samples showing type IV isotherms, synthesised using $2 \mathrm{M} \mathrm{HNO}_{3}$ and: (i) $80 \mathrm{mM}$ TTIP, (ii) $160 \mathrm{mM}$ TTIP and (iii) $650 \mathrm{mM}$ TTIP respectively; (c) nitrogen adsorption-desorption isotherms of mesoporous $\mathrm{FMS} \mathrm{TiO}_{2}$ sub-microspheres ( $2 \mathrm{M} \mathrm{HNO} / 160 \mathrm{mM}$ TTIP) after (i) no further treatment or calcination at: (ii) $300^{\circ} \mathrm{C}$, (iii) $400^{\circ} \mathrm{C}$ and (iv) $500^{\circ} \mathrm{C}$; (d) QS-DFT calculation of the pore size distribution performed on the adsorption branch of the respective isotherms (i)-(iv) shown in (c). 
and mesopores in the range $2.5-6 \mathrm{~nm}$. The same analyses performed on the microporous samples prepared using $1 \mathrm{M} \mathrm{HNO}_{3}$ revealed only the presence of pores between 1-1.8 $\mathrm{nm}$ across (ESI, Fig. S13†).

As expected, calcination dramatically reduces the surface area to values comparable to those reported for crystalline bulk anatase. The growth of the crystallites progressively removes the porosity and narrows the hysteresis loops (Fig. 6c). The analysis of the pore size distribution as a function of the calcination temperature (Fig. 6d) confirmed the progressive disappearance of the micropores followed by the mesopores. The micropores likely arise from the voids between crystallites, which diminish as the grains grow, although it is also possible that the smaller cavities could nucleate or combine, shifting the distribution towards larger values before further densification.

\section{Impurities and surface characterisation}

The IR spectra reflect how the surfaces of the as-made FMS submicrospheres bear some of the functionalities associated with the starting reagents. Analysis of the as-synthesised submicrospheres (ESI, Fig. S14a $\dagger$ ) revealed the presence of hydroxylated surfaces, with broad signals between 3600$3200 \mathrm{~cm}^{-1}$ and the band at $1640-1623 \mathrm{~cm}^{-1}$ indicating the stretching and bending modes respectively of $\mathrm{O}-\mathrm{H}$ in water. ${ }^{57}$ Bands at 1222,1137 and $1048 \mathrm{~cm}^{-1}$ could be attributed to $\delta(\mathrm{Ti}-$ $\mathrm{OH}$ ) vibrations as seen in the presence of strong $\mathrm{H}$-bonding with water molecules such as in $\mathrm{TiO}_{2}$ produced by sol-gel methods. ${ }^{58}$ Other bands could be assigned to $\mathrm{C}=\mathrm{O}$ stretching modes from free carboxylic acid groups $\left(\mathrm{ca} .1715 \mathrm{~cm}^{-1}\right)$ and $\mathrm{Ti}-\mathrm{O}-\mathrm{C}$ bridging vibrations $\left(1080 \mathrm{~cm}^{-1}\right)$ just as have been observed previously in sol-gel-derived $\mathrm{TiO}_{2}$ using complexed forms of TTIP as a precursor. ${ }^{59}$ Similarly, the use of $\mathrm{HNO}_{3}$ led to further IR modes indicating nitrates $\left(1350 \mathrm{~cm}^{-1}\right)$ and nitrites $\left(1260 \mathrm{~cm}^{-1}\right) .{ }^{60}$ Apart from these decomposition products of $\mathrm{HNO}_{3}$, which are generally observed in nitric acid-mediated syntheses, ${ }^{61}$ the presence of adsorbed molecules of the acid itself cannot be excluded, since its strong IR signature at $1711 \mathrm{~cm}^{-1}$ in the gas phase is reported to shift to $1677 \mathrm{~cm}^{-1}$ when the molecule is adsorbed to a surface. ${ }^{62}$ Not surprisingly, calcination has the effect of removing all the functionalities observed in the as- made materials, with all the respective IR bands absent after treatment at $600{ }^{\circ} \mathrm{C}$ (ESI, Fig. S14b $\dagger$ ).

XPS analysis provided additional information about the surface composition of the as-synthesised samples (ESI, Fig. S15 and $\left.\mathrm{S} 16^{\dagger}\right)$. The characteristic signals of $\mathrm{Ti}^{4+}$ species were observed at $c a .458 \mathrm{eV}\left(2 \mathrm{p}_{3 / 2}\right)$ and $c a .465 \mathrm{eV}\left(2 \mathrm{p}_{1 / 2}\right)$. However, small peaks at lower and higher binding energy (ca. $456.9 \mathrm{eV}$ and $460.6 \mathrm{eV}$ ) of the main $2 \mathrm{p}_{3 / 2}$ component were also observed in the high resolution Ti $2 p$ spectrum as shown in Fig. S16c. $\dagger$ These have been observed previously and are associated with non-stoichiometric defects, such as $\mathrm{Ti}^{3+}$ and $\mathrm{Ti}^{2+} \cdot{ }^{63,64} \mathrm{~A}$ broad peak at $529.5 \mathrm{eV}$ is consistent with the $\mathrm{O} 1 \mathrm{~s}$ binding energy for $\mathrm{O}^{2-}$ in $\mathrm{TiO}_{2}$ (528.5-529.7 eV). ${ }^{65}$ The broadening of this peak could be attributed to secondary contributions at $532 \mathrm{eV}$ from adsorbed oxygen on the $\mathrm{TiO}_{2}$ surfaces (530.5-533.8 eV) ${ }^{66} \mathrm{~A}$ quantitative estimation of the $\mathrm{C}$ and $\mathrm{N}$-based impurities in the as-synthesised particles was performed by comparing data from combustion microanalysis and depth profile XPS analyses. Combustion microanalyses confirmed the presence of traces of $\mathrm{N}$ (ca. $1 \mathrm{wt} \%$ ) and $\mathrm{C}$ content ranging from 1.5-3.5 wt\% (ESI, Table S4 $\dagger$ ). XPS depth profile analysis via Ar etching of the particle surfaces was performed (Table S5 $\dagger$ ). After etching to $10 \mathrm{~nm}$, the amount of $\mathrm{C}$ is reduced with a concomitant increase in Ti and O. The XPS results are influenced by the contamination of the carbon tape used to prepare the samples. However, the shift of the C 1s peak towards lower binding energies (ESI, Fig. S16a $\dagger$ ) and especially the large reduction in the carbon signal during etching shows that samples as synthesised -i.e. before etching - contain large amounts of adventitious carbon at the surface. The presence of nitrogen is not observable in the as-synthesised sample because of this carbon contamination, but after etching a small $\mathrm{N}$ signal shows the samples are lightly doped $(<1 \%$, Table S6 $\dagger$ ) with $\mathrm{N}$, consistent with the combustion analysis. The high-resolution $\mathrm{N}$ 1s signal (ESI, Fig. S16e $\dagger$ ) shows a binding energy of $c a .400 \mathrm{eV}$ consistent with substitutional nitride species in the oxide lattice. ${ }^{67}$

The presence of volatile products was evaluated by simultaneous TG-DTA coupled to MS for evolved gas analysis. Fig. 7 shows the mass loss of the sub-microspheres to be $10-20 \%$ depending on the synthesis conditions, as compared to negligible mass losses for commercial anatase or P25 under the same

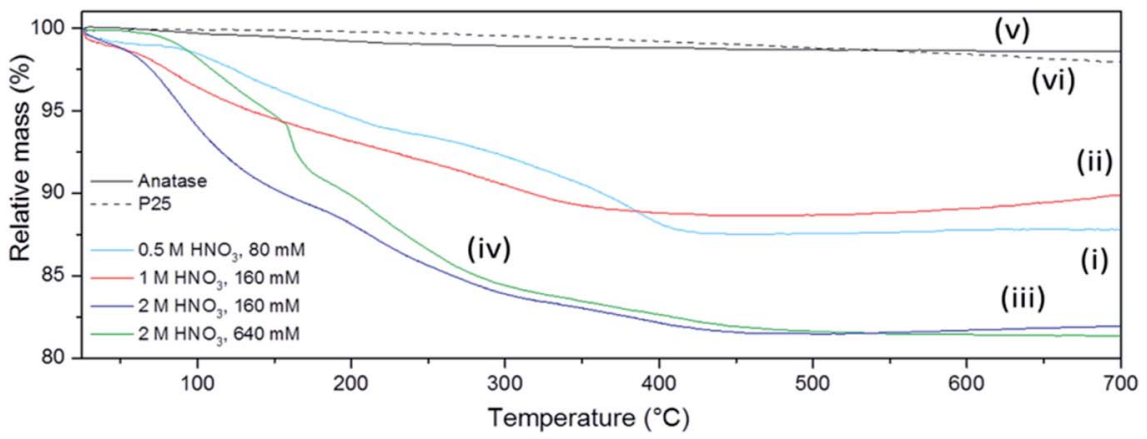

Fig. 7 Thermogravimetric (TG) profiles of selected as-prepared $\mathrm{FMS}-\mathrm{TiO}_{2}$ samples ( 1 min $\mathrm{MW}$ irradiation) synthesised with (i) $0.5 \mathrm{M}$ HNO${ }_{3} /$ $80 \mathrm{mM}$ TTIP, (ii) $1 \mathrm{M} \mathrm{HNO}_{3} / 160 \mathrm{mM} \mathrm{TTIP}$, (iii) $2 \mathrm{M} \mathrm{HNO}_{3} / 160 \mathrm{mM} \mathrm{TTIP}$, (iv) $2 \mathrm{M} \mathrm{HNO}_{3} / 640 \mathrm{mM} \mathrm{TTIP}$ in comparison to (v) commercial anatase and (vi) Aeroxide ${ }^{\circ}$ P25 respectively. 

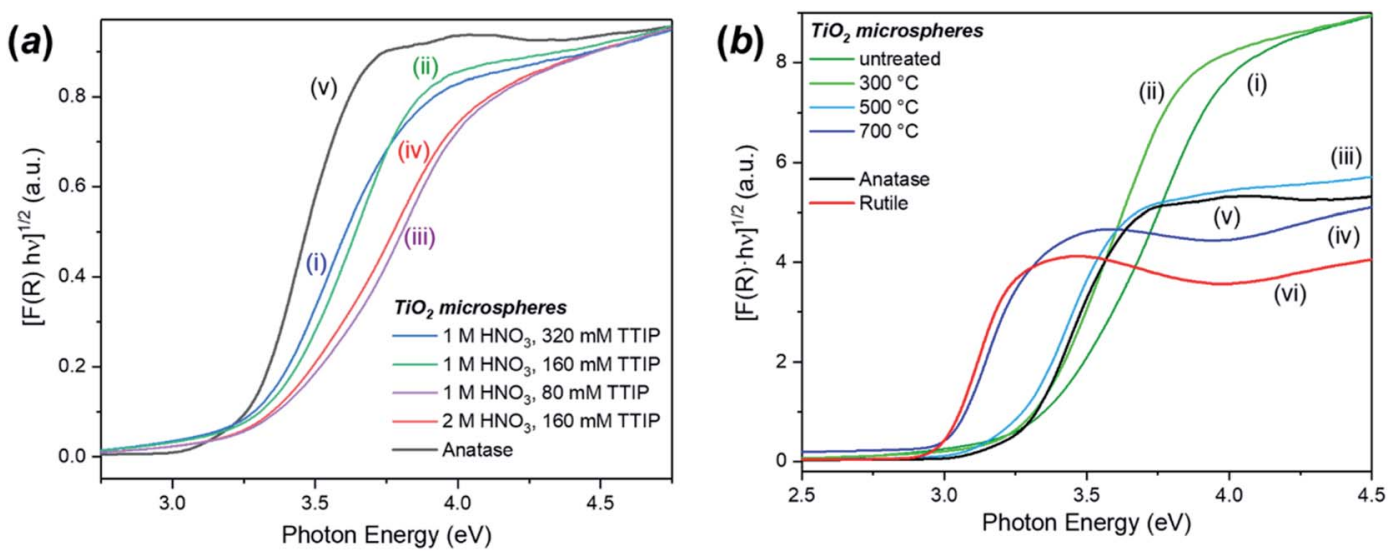

Fig. 8 Kubelka-Munk plots for the calculation of the indirect band gap for: (a) selected samples of as-made $\mathrm{FMS} \mathrm{TiO}_{2}$ sub-microspheres prepared using: (i) $1 \mathrm{M} \mathrm{HNO}_{3} / 320 \mathrm{mM}$ TTIP, (ii) $1 \mathrm{M} \mathrm{HNO}_{3} / 160 \mathrm{mM}$ TTIP, (iii) $1 \mathrm{M} \mathrm{HNO}_{3} / 80 \mathrm{mM}$ TTIP and (iv) $2 \mathrm{M} \mathrm{HNO}_{3} / 160 \mathrm{mM}$ TTIP respectively as compared to (v) commercial $\mathrm{TiO}_{2}$ anatase and (b) a representative sample of $\mathrm{FMS} \mathrm{TiO}_{2}$ sub-microspheres $\left(2 \mathrm{M} \mathrm{HNO}_{3} / 160 \mathrm{mM}\right.$ TTIP): (i) asmade and calcined at (ii) $300{ }^{\circ} \mathrm{C}$, (iii) $500^{\circ} \mathrm{C}$, (iv) $700{ }^{\circ} \mathrm{C}$, respectively. The plots are compared to those for commercial samples of (v) anatase and (vi) rutile $\mathrm{TiO}_{2}$.

conditions. Nearly $\frac{3}{4}$ of the total mass loss for the submicrospheres occurred before $300{ }^{\circ} \mathrm{C}$, whereas after $500{ }^{\circ} \mathrm{C}$ no further mass loss was detected. This mass loss can be mainly attributed to the release of adsorbed water and unbound acid molecules (up to $c a .150{ }^{\circ} \mathrm{C}$ ) and to structural water (up to $c a$. $\left.250{ }^{\circ} \mathrm{C}\right) .^{68}$ The signal of this released water was not incontrovertibly detected by evolved gas MS analysis as it is probably masked by the dominant signal of the carrier gas (Ar). The presence of $\mathrm{NO}$ and likely $\mathrm{N}_{2} \mathrm{O}$ could be detected (ESI, Fig. S17 $\dagger$ ), although the presence of $\mathrm{CO}_{2}$ cannot be excluded (given its similar molecular weight to $\mathrm{N}_{2} \mathrm{O}$ ). These signals are therefore consistent with IR data and $\mathrm{HNO}_{3}$ decomposition products, which have been previously reported to desorb within the observed temperature range. ${ }^{68}$

\section{Optical properties}

The DR-UV-Vis analysis of the as-synthesised FMS-TiO ${ }_{2}$ showed a variation in band gap compared to bulk crystalline anatase and the shape of the absorbance spectrum (and the associated Kubelka-Munk functions) was notably different when compared to that of the commercial anatase reference sample (Fig. 8). Calculation of indirect and direct band gaps across FMS samples consistently gave values of $c a .3 .3-3.4 \mathrm{eV}$ and 3.6-3.8 eV respectively (ESI, Table S6 $\dagger$ ), which are significantly larger than the values obtained for anatase (indirect band gap of $3.23 \mathrm{eV}$, direct band gap of $3.47 \mathrm{eV}$ ). A closer study of the correlation between band gap and synthesis conditions indicated that increasing the precursor concentration tends to decrease the band gap systematically. However, a correlation of band gap with acidity is not so clear, although there is a general trend of increasing band gap with increasing acidity (Fig. 9 and ESI, Fig. S18 $\dagger$ ). One possible rationalisation relates to correlations of band gap with crystallite size. An increase in precursor concentration leads to a decrease in crystallite size (as is apparent from analysis of the $E_{g, I}$ mode in Raman spectra, for example). An opening of the band gap is expected from quantum confinement effects for particles $<5 \mathrm{~nm}$ in diameter. ${ }^{69,70} \mathrm{~A}$ higher concentration of precursor molecules might be expected to generate a large number of nuclei, leading to smaller crystallites and particles. ${ }^{71,72}$ However, in the acidic reaction environment under MW heating, such competition can be suppressed and agglomeration of the seed crystallites to minimise the energy of the system, would occur..$^{73}$ The band gap would consequently decrease with precursor concentration under such conditions. The trends above are consistent with our observations from PXD, Raman spectroscopy and SEM/TEM where the primary and secondary structures of the $\mathrm{FMS}-\mathrm{TiO}_{2}$ materials (i.e. both the sub-microspheres and their component nanocrystallites) increase in size with increasing precursor concentration, while overall they tend to decrease in size with increasing acid concentration (ESI, Fig. S5†).

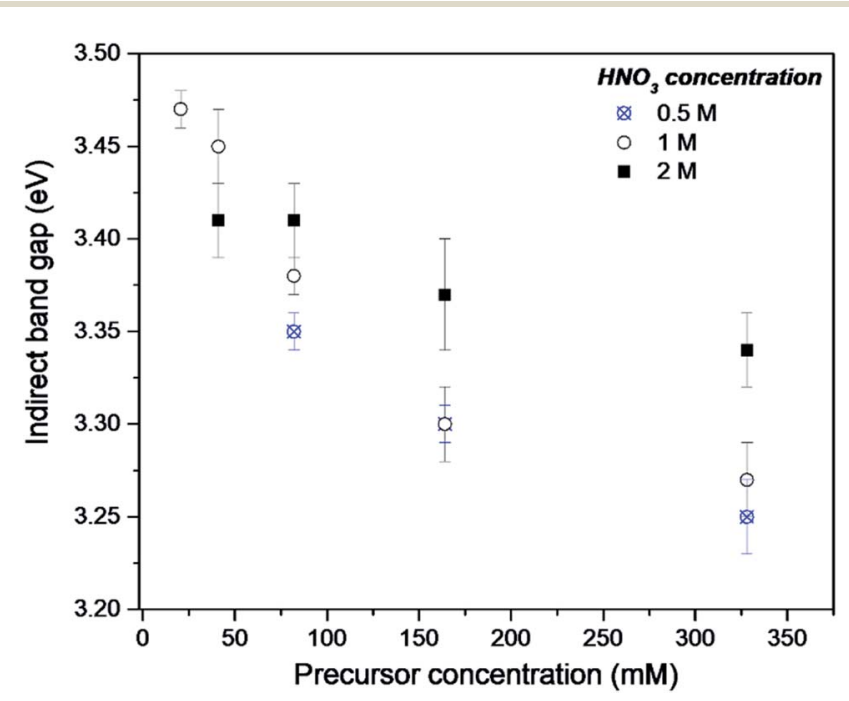

Fig. 9 Indirect band gap values for as-made $\mathrm{FMS}-\mathrm{TIO}_{2}$ sub-microspheres as a function of TTIP concentration using $0.5 \mathrm{M}$ (crosses/ circles), $1 \mathrm{M}$ (open circles) or $2 \mathrm{M}$ (filled squares) $\mathrm{HNO}_{3}$ respectively. 

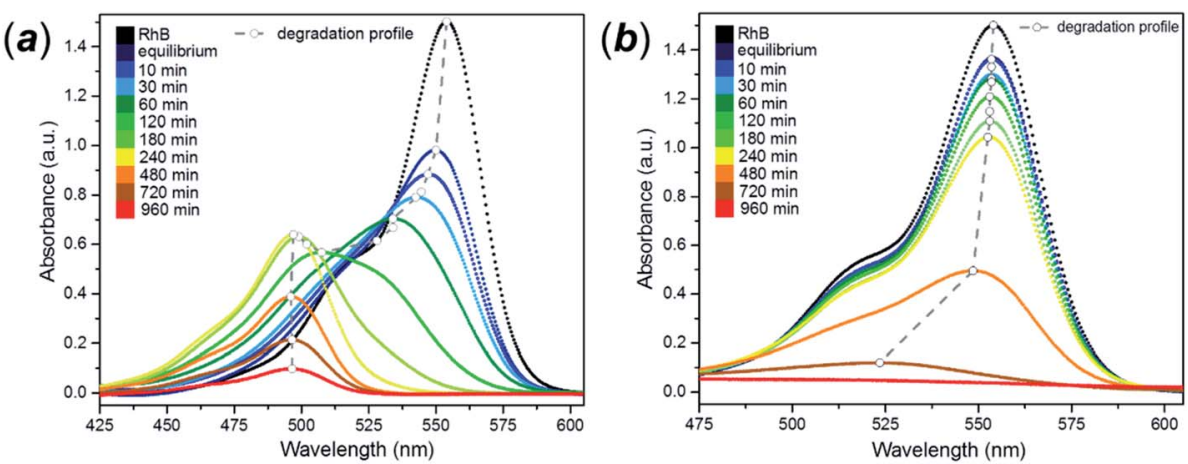

Fig. 10 Rhodamine UV-Vis absorbance spectra using: (a) as-made $\mathrm{FMS} \mathrm{TiO}_{2}$ sub-microspheres ( $2 \mathrm{M} \mathrm{HNO}_{3}$ conc. and 320 mM precursor conc.) and (b) P25 as a catalyst for its degradation under visible light. The dashed trend line indicates the shift in the maximum of the principal peak in each spectrum.

The increase in band gap for the $\mathrm{FMS}^{-\mathrm{TiO}_{2}}$ materials when compared to commercial anatase is a further indicator of the presence of nanocrystallites in the spheres. Fig. $8 \mathrm{~b}$ (with data also reported in Table 1) shows how calcination at increasing temperatures (leading to increasing crystallite size) reduces the band gap. The DR-UV-Vis spectra become increasingly similar to that of bulk anatase with higher calcination temperature until ultimately at $700{ }^{\circ} \mathrm{C}$ the spectrum resembles that of bulk rutile, with a comparable (reduced) band gap.

\section{Photocatalytic tests}

The photocatalytic behaviour of the FMS materials was evaluated in the aqueous phase by considering the controlled degradation of rhodamine $\mathrm{B}(\mathrm{RhB})$. The dye is very stable in aqueous solution without the presence of a photocatalyst, when irradiated with either UVA or visible light. A universal characteristic of the photodegradation experiments was the immediate decrease in the RhB concentration prior to irradiation, during the induction period of the experiment (sonication/ stirring in the absence of light to improve the dispersion of the catalyst in the suspension). The dramatic $c a .80 \%$ drop in dye concentration indicated adsorption of the dye molecules on the surface of the spheres. By comparison, P25 gave only a $c a .2-$ $3 \%$ decrease in dye concentration during the induction period (ESI, Fig. S19†). The colouration of the $\mathrm{FMS} \mathrm{TiO}_{2}$ samples clearly indicated a strong adsorption of the dye by the particles. The enhanced proclivity for adsorption is readily rationalised by the remarkable surface area $\left(200-500 \mathrm{~m}^{2} \mathrm{~g}^{-1}\right)$ of the submicrospheres as compared with values typically an order of magnitude lower for P25 (ca. $\left.50 \mathrm{~m}^{2} \mathrm{~g}^{-1}\right) .^{74}$

The as-synthesised spheres showed no evidence of photodegradation under UVA light (ESI, Fig. S20†), whereas under visible light a continuous change in the colour of the solution occurred from purple to yellow (ESI, Fig. S21†) Generally, dye degradation using $\mathrm{TiO}_{2}$-based catalysts (e.g. Aeroxide $\left.{ }^{\circledR} \mathrm{P} 25\right)$ is manifested by a decolouration of the original solution, with a fade in colour with exposure time. UV-Vis absorption spectra taken for samples of $\mathrm{RhB} / \mathrm{FMS}-\mathrm{TiO}_{2} v s$. time during the experiment showed an hypsochromic shift of the maximum absorbance peak to lower wavelength (from $\lambda=554 \mathrm{~nm}$ to $498 \mathrm{~nm}$;
Fig. 10a) simultaneous with a reduction in peak intensity. Consistent with visual observations of the corresponding experiment, no such hypsochromic shift occurs for dye degradation using P25 until just before the end point, when a small shift to $525 \mathrm{~nm}$ is observed (at which point the concentration of rhodamine is barely detectable and the solution is transparent; Fig. 10b). After $3 \mathrm{~h}$ calcination in air at temperatures of 400$600{ }^{\circ} \mathrm{C}$, the $\mathrm{TiO}_{2}$ sub-microspheres showed improved photocatalytic activity under UVA light but lost all trace of photoactivity under visible light (ESI, Fig. S22†).

\section{Photodegradation mechanism}

\section{Selective $\boldsymbol{N}$-deethylation of rhodamine}

Photodegradation of $\mathrm{RhB}$ can be proceed via two different and independent mechanisms; the direct degradation of the chromophoric conjugated system or the de-ethylation of the four ethyl groups. Direct degradation typically occurs in conventional photocatalytic processes. De-ethylation has been described as an indirect photocatalytic process, as it can occur side by side with the chromophoric cleavage, but it requires a direct chemical contact between the catalyst surface and the dye molecule, allowing the transfer of an electron to the conduction band of the photocatalyst. According to the proposed mechanism, the $N$-ethyl group of the dye provides a free electron pair necessary for the chemisorption. ${ }^{75}$ While in many catalytic degradation experiments the two processes occur simultaneously, the visible light degradation of $\mathrm{RhB}$ in the presence of $\mathrm{FMS}-\mathrm{TiO}_{2}$ appears to follow a selective deethylation mechanism until the formation of a product similar to 3,6-diamino-9-(2-carboxyphenyl) chloride, known also as rhodamine $110,{ }^{76}$ occurs with an absorbance peak maximum at $498 \mathrm{~nm}$. The intermediate de-ethylated fragments present absorbance peaks at $539 \mathrm{~nm}, 522 \mathrm{~nm}$ and $510 \mathrm{~nm} .{ }^{77}$ The sequential $N$-de-ethylation of the original molecule causes colour changes until the end of the process when the fully deethylated form of rhodamine (Rh110) undergoes the cleavage of the conjugated xanthene unit, ultimately leading to the fading of the solution. ${ }^{78}$ Fig. 11 presents the P25 and FMS- $\mathrm{TiO}_{2}$ degradation experiments from the perspective of the different 
(a)

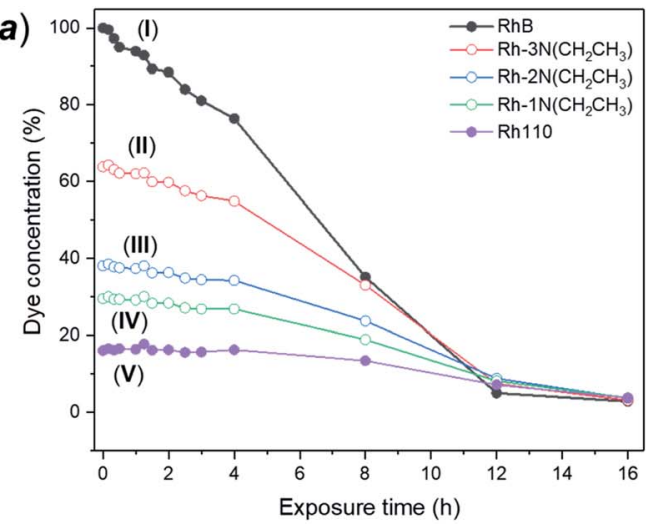

(b)

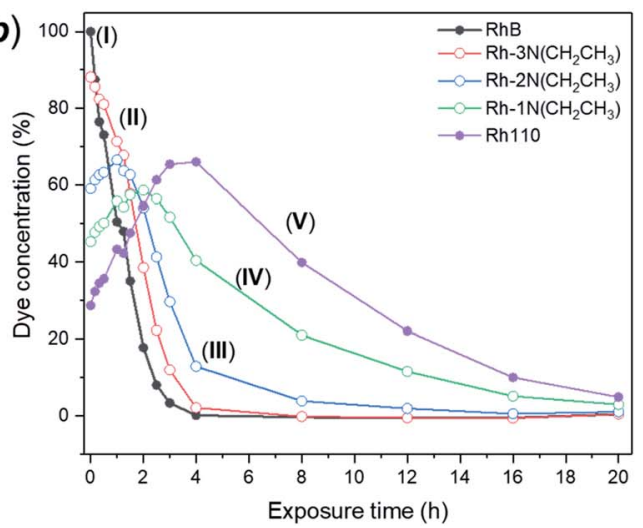

Fig. 11 (a) Degradation curves for the 5 degrees of $N$-ethylation of the Rhodamine molecule (where (I) RhB contains $4 \mathrm{~N}$-ethyl groups and (V) Rh110 contains none) for: (a) P25 and (b) as-made FMS TiO 2 sub-microspheres under visible light irradiation; (I) RhB, (II) Rh-3N-Et, (III) Rh-2NEt, (IV) Rh-1N-Et, (V) Rh110.

degrees of $N$-ethylation of RhB, by considering the intensity of peaks centred at the absorption wavelengths of each of the reported "intermediate" de-ethylated rhodamine molecules (i.e. in which 1, 2, 3 or 4 ethyl groups are removed). When using P25 (Fig. 11a), the degradation behaviour for each of the deethylated decomposition products is rather similar, with the concentrations decreasing uniformly with time. Conversely, for FMS-TiO ${ }_{2}$ (Fig. $11 \mathrm{~b}$ ) the tri- and di-ethylated molecules are formed and removed extremely rapidly, followed by the relatively sharp degradation of the mono N-ethylated intermediate and the de-ethylated molecule (Rh 110).

Given that no meaningful hypsochromic shift was observed in the degradation experiment performed in the presence of P25, observation of the absorption spectra (and solution colour) leads one to speculate about the predominance of the cleavage mechanism over de-ethylation. In the presence of FMS-TiO ${ }_{2}$, the initial de-ethylation and the cleavage proceeded at different rates, with the latter mechanism prevailing only on the completion of the former. A similar degradation pathway has been reported for nanocrystalline anatase $\mathrm{TiO}_{2}$ by Fan et al. ${ }^{79}$ The authors reported how a low degree of crystallinity, high surface area (over $200 \mathrm{~m}^{2} \mathrm{~g}^{-1}$ ) and crystallite diameters $<10 \mathrm{~nm}$ led to predominance of $\mathrm{N}$-de-ethylation over chromophoric cleavage, but no further explanation of the phenomenon could be offered at the time. The above behaviour coupled with the lack of $\mathrm{FMS}^{-\mathrm{TiO}_{2}}$ UVA photoactivity suggests that the dye degradation mechanism bears analogies to that which occurs in the presence of vanadyl ions. According to this mechanism, the FMS- $\mathrm{TiO}_{2}$ particles would act as electron acceptors, with photodegradation induced by the excitation of the dye in solution rather than by photogeneration of electrons and holes in the particles. In this situation, the catalyst acts as an electrontransfer mediator, with electrons in the conduction band reacting with oxygen adsorbed on the catalyst surface forming radical species, such as $\mathrm{O}, \mathrm{OOH}^{-}$and $\mathrm{HO}$, where the last of these is responsible for advancing the degradation, particularly via chromophore cleavage. ${ }^{80}$

Hypsochromic shifts have indeed been observed in singleelectron transfer process such as the reduction of $\mathrm{VO}_{2}{ }^{+}$under visible light irradiation. The prevalence of $N$-deethylation over chromophore cleavage can be understood in terms of the passage of an electron from the excited state of $\mathrm{RhB}$ to $\mathrm{VO}_{2}{ }^{+}$(i.e. containing $\mathrm{V}$ in the +5 oxidation state; pervanadyl). The reduced vanadium species $\left(\mathrm{VO}^{2+}\right.$, vanadyl) are incapable of further electron trapping, hence showing no activity. The same study reported an absence of de-ethylation under UV light when a carboxyl moiety is present on the aromatic molecule. ${ }^{81}$ In this case, the electron transfer would occur preferentially with species able to coordinate with the carboxyl, such as $\mathrm{Pt}(\mathrm{Iv}) .{ }^{82}$

\section{Effect of the structure}

Brookite can be also involved in dye photodegradation under visible light and the presence of brookite nanocrystals in FMS$\mathrm{TiO}_{2}$ may be significant in the degradation mechanism. Although the photocatalytic behaviour of brookite as compared to anatase is still under debate, ${ }^{83}$ junctions between the two $\mathrm{TiO}_{2}$ polymorphs have been identified as enhancing the photoactivity when compared to the single phases. ${ }^{83,84}$ Brookite has a slightly larger band gap than anatase and the band energy matching of the two polymorphs facilitates the interfacial migration of photoinduced electrons from brookite to anatase. ${ }^{85}$ The junctions act as one-way valves for the charge carriers, to some extent inhibiting their recombination. ${ }^{82}$ However, the behaviour of such brookite-anatase junctions can apparently be very interface-dependent and the possibility of electron-hole pair recombination is often relatively high in a random phase mixture, for example, which leads in turn to inefficient charge separation and a consequent deterioration of photocatalytic and photoelectrochemical properties. ${ }^{\mathbf{8 6 , 8 7}}$

Considering the lesser photocatalytic performance of the assynthesised $\mathrm{FMS}^{-\mathrm{TiO}_{2}}$ samples under UVA light, it is possible that the presence of amorphous domains in the particle structure is responsible for this behaviour. The reduced photocatalytic performance of amorphous $v s$. crystalline $\mathrm{TiO}_{2}$ is generally attributed to a high concentration of defects, which enhance the electron-hole recombination rate.$^{88}$ Higher crystallinity and a higher concentration of larger anatase 
crystallites, such as is achieved by the calcination of the FMS$\mathrm{TiO}_{2}$ samples, should therefore enhance the photoactivity under UVA light. Conversely, the visible light photoactivity of the FMS samples would be expected to decrease on sintering, not least since an increase in crystallite size leads to the bulk recombination of charge carriers as the diffusion path length for the charges to migrate to the surface increases. ${ }^{89}$ The loss of photoactivity could be also related to the reduction in surface area and the absence of available sites for electron transfer. Although the surface area of some calcined samples remains higher than P25, other factors may affect the degradation mechanism. For instance, the stability of the dispersions of FMS samples in aqueous solution decreased with increasing calcination temperature, with a zeta potential shifting towards progressively less-negative values (ESI; Table S7†). The poorer dispersion stability and lower adsorption capacity of cationic organic pollutants close to neutral $\mathrm{pH}$ are detrimental for the photocatalytic performance of the particles. ${ }^{90}$

\section{Adsorption and sensitisation mechanism}

The observation of the purple coloration of the $\mathrm{FMS}^{-\mathrm{TIO}_{2}}$ at the end of the degradation experiment reinforces the importance of the surface adsorption in the degradation mechanism. The high specific surface area of the spheres leads to higher initial adsorption ( $\mathrm{ca} .20 \%$ ) during the equilibration phase compared with P25. Similar values of initial adsorption have been reported previously for $\mathrm{TiO}_{2}$ particles with rather similar physicochemical properties. ${ }^{79}$ The enhanced initial adsorption of the spheres presents further evidence for the nature of the degradation mechanism. Assuming the spheres possess a slightly negative surface charge in water at neutral $\mathrm{pH}$ (the $\mathrm{p} K_{\mathrm{a}}$ of $\mathrm{TiO}_{2}$ is estimated to be $c a$. 5.5-6.5), ${ }^{91}$ then the carboxyl moieties of RhB molecules, with a $\mathrm{p} K_{\mathrm{a}}$ of $3.22,{ }^{92}$ will be deprotonated, hence repulsion between the spheres and the Rhodamine occurs. ${ }^{93}$ The electrostatic repulsion is mitigated by the high surface area of the FMS-TiO compensate the effect. The phenomenon could also explain the charge transfer process involved in the de-ethylation, since the molecule could adhere to the $\mathrm{TiO}_{2}$ surface preferentially through the positively charged nitrogen atoms of the $\mathrm{N}$-ethyl moieties. The selectivity of degradation via de-ethylation vs. chromophoric cleavage has been reported to depend on the $\mathrm{pH}$ of the RhB solution when using either $\mathrm{Pb}_{3} \mathrm{Nb}_{4} \mathrm{O}_{13}$ pyrochlore supported on fumed silica ${ }^{94}$ or a $\mathrm{TiO}_{2} / \mathrm{SiO}_{2}$ composite, ${ }^{95}$ with electron transfer facilitated by the molecule orientation.

The process of electron injection into the semiconductor conduction band is well-known for photoexcited dyes and is an underpinning principle in the design of dye-sensitized solar cells (DSSCs) in which a semiconducting oxide (commonly $\mathrm{TiO}_{2}$ ) is sensitised by dye adsorption..$^{96}$ From the evident colour of the spheres at the end of RhB degradation, the RhB molecules adsorbed to the $\mathrm{TiO}_{2}$ particle surface remain undegraded. The adsorption phenomenon could thus be understood in terms of a dye-sensitisation, in which the presence of the dye enhances the electron transfer and the degradation process of other molecules in solution.

\section{Conclusions}

Flash microwave-assisted solvothermal (FMS) synthesis is an efficient new method for the ultra-fast preparation of nanostructured, phase-pure mesoporous $\mathrm{TiO}_{2}$ spherical submicroparticles. The spherical particle diameter can be tuned from $2 \mu \mathrm{m}$ to as small as $200 \mathrm{~nm}$ by manipulation of the synthesis parameters (e.g. acid and precursor concentration). The particles possess a complex hierarchical structure of nanocrystallites (of the order of $10 \mathrm{~nm}$ or less as indicated by multiple characterisation techniques and property measurements) with an exceptionally high surface area $\left(200-500 \mathrm{~m}^{2} \mathrm{~g}^{-1}\right)$ and predominant mesoporosity. The particles form within a narrow size distribution even after only 1 minute of MW treatment and prove to have high dispersibility in aqueous media. This attractive combination of features enhances RhB adsorption and has profound effects on the subsequent photodegradation process. Unlike P25, which by contrast preferentially degrades $\mathrm{RhB}$ by chromophoric cleavage, the assynthesised sub-microspheres exhibit rapid and selective degradation via $\mathrm{N}$-de-ethylation. Calcination destroys the visible light activity of the spheres as the porosity and surface area are lost. However, one cannot completely rule out the significance of the surface "impurity" species present in the as-made FMS$\mathrm{TiO}_{2}$ prior to calcination. Further experiments which can decouple the potential surface functionalisation chemistry from the structural characteristics of the $\mathrm{TiO}_{2}$ spheres themselves should shed further light on the mode by which the degradation reactions proceed and how one might improve the $\mathrm{FMS}-\mathrm{TiO}_{2}$ catalytic properties further. Moreover, the structural attributes of the $\mathrm{FMS}-\mathrm{TiO}_{2}$ spheres and the ease with which they can be made, paves the way for further advances in a myriad of titaniarelated applications. In fact, the scope could be immense if the FMS technique can be applied more widely in the synthesis of mesoporous inorganic oxides.

\section{Conflicts of interest}

There are no conflicts to declare.

\section{Acknowledgements}

DHG thanks the University of Glasgow for a Lord Kelvin-Adam Smith Scholarship for MDC. The authors also thank Mr Colin How and Mr Peter Chung from the University of Glasgow for assistance with TEM and SEM experiments respectively and Dr Martin Rosillo-Lopez, UCL for input on XPS Ar etching.

\section{Notes and references}

1 J. H. Braun, A. Baidins and R. E. Marganski, Prog. Org. Coat., 1992, 20, 105.

2 T. G. Smijs and S. Pavel, Nanotechnol., Sci. Appl., 2011, 4, 95.

3 M. Skocaj, M. Filipic, J. Petkovic and S. Novak, Radiol. Oncol., 2011, 45, 227. 
4 J. Schneider, M. Matsuoka, M. Takeuchi, J. Zhang, Y. Horiuchi, M. Anpo and D. W. Bahnemann, Chem. Rev., 2014, 114, 9919.

5 M. R. Hoffmann, S. T. Martin, W. Choi and D. W. Bahnemann, Chem. Rev., 1995, 95, 69.

6 A. M. Kalsin, M. Fialkowski, M. Paszewski, S. K. Smoukov, K. J. M. Bishop and B. A. Grzybowski, Science, 2006, 312, 420.

7 Z. Li, Y. Que, L. Mo, W. Chen, Y. Ding, Y. Ma, L. Jiang, L. Hu and S. Dai, ACS Appl. Mater. Interfaces, 2015, 7, 10928.

8 H. Y. Wang, J. Chen, S. Hy, L. Yu, Z. Xu and B. Liu, Nanoscale, 2014, 6, 14926.

9 J. Wang, Y. Zhou, Y. Hu, R. O'Hayre and Z. Shao, J. Phys. Chem. C, 2011, 115, 2529.

10 W. A. Jacobi, Environ. Sci. Technol., 1998, 32, 2650.

11 X. Zhang, J. H. Pan, A. J. Du, J. Ng, D. D. Sun and J. O. Leckie, Mater. Res. Bull., 2009, 44, 1070.

12 T. C. Long, N. Saleh, R. D. Tilton, G. V. Lowry and B. Veronesi, Environ. Sci. Technol., 2006, 40, 4346.

13 M. Bundschuh, Environ. Sci. Eur., 2018, 1-17.

14 X. Wang, J. C. Yu, C. Ho, Y. Hou and X. Fu, Langmuir, 2005, 21, 2552.

15 G. J. de A. A. Soler-Ilia, A. Louis and C. Sanchez, Chem. Mater., 2002, 14, 750.

16 P. Yang, D. Zhao, D. I. Margolese, B. F. Chmelka and G. D. Stucky, Nature, 1998, 396, 152.

17 S. M. Mahpeykar, J. Koohsorkhi and H. Ghafoori-fard, Nanotechnology, 2012, 23, 165602.

18 T. Calliot, G. Pourroy and D. Stuerga, J. Solid State Chem., 2004, 177, 3843.

19 C. Bosquet-Berthelin, D. Chaumont and D. Stuerga, J. Solid State Chem., 2008, 181, 616.

20 E. Gressel-Michael, D. Chaumont and D. Stuerga, J. Colloid Interface Sci., 2005, 285, 674.

21 V. M. Ramakrishnan, S. Pitchaiya, N. Muthukumarasamy, K. Kvamme, G. Rajesh, S. Agilan, A. Pugazhendhi and D. Velauthapillai, Int. J. Hydrogen Energy, 2020, 45, 2703627046.

22 W. Yue, X. Xu, J. T. S. Irvine, P. S. Attidekou, C. Liu, H. He, D. Zhao and W. Zhou, Chem. Mater., 2009, 21, 2540.

23 K. Lan, R. Wang, W. Zhang, Z. Zhao, A. Elzatahry, X. Zhang, Y. Liu, D. Al-Dhayan, Y. Xia and D. Zhao, Chem, 2018, 4, 2436.

24 J. Yoshida, Flash Chemistry: Fast Organic Synthesis in Microsystems, Wiley, 2008.

25 I. Bennour, A. M. Cioran, F. Teixidor and C. Viñas, Green Chem., 2019, 21, 1925.

26 M. Cirillo, T. Aubert, R. Gomes, R. Van Deun, P. Emplit, A. Biermann, H. Lange, C. Thomsen, E. Brainis and Z. Hens, Chem. Mater., 2014, 26, 1154.

27 Y. Q. Xu, S. W. Du, J. Gao, Y. Cao, C. G. Chen and X. H. Xian, Adv. Mater. Res., 2013, 750-752, 228.

28 K. Bellon, D. Chaumont and D. Stuerga, J. Mater. Res., 2001, 16, 2619.

29 Y. Kitamura, N. Okinaka, O. O. P. Mahaney, D. Kusano, B. Ohtani and T. Akiyama, J. Alloys Compd., 2008, 455, L1.

30 J. Aldabe, C. Santamaría, D. Elustondo, E. Lasherasa and J. M. Santamaría, Anal. Methods, 2013, 5, 554.
31 Y.-J. Zhu and F. Chen, Chem. Rev., 2014, 114, 6462.

32 C. Gabriel, S. Gabriel, E. H. Grant, B. S. J. Halstead and D. M. P. Mingos, Chem. Soc. Rev., 1998, 27, 213.

33 G. D. Robertson, D. M. Mason and W. H. Corcoran, J. Phys. Chem., 1955, 59, 683.

34 C. L. Gordon, W. G. Schlecht and E. Wichers, J. Res. Natl. Bur. Stand., 1944, 33, 457.

35 S. Komarneni, R. K. Rajha and H. Katuski, Mater. Chem. Phys., 1999, 61, 50.

36 C. J. Cadman, A. Pucci, F. Cellesi and N. Tirelli, Adv. Funct. Mater., 2014, 24, 993.

37 M. Hu, C. Bai, M. Song, X. Lv, S. Zhang and G. Qiu, Int. J. Remote Sensing Appl., 2012, 2, 31.

38 J. R. Rangel-Mendez, J. Matos, L. F. Chazaro-Ruiz, A. C. Gonzalez-Castillo and G. Barros-Yanez, Appl. Surf. Sci., 2018, 434, 744.

39 G. S. Falk, S. Y. Gomez-Gonzalez and D. Hotza, Mater. Lett., 2020, 278, 128418.

40 J. M. Hanlon, L. B. Diaz, G. Balducci, B. A. Stobbs, M. Bielewski, P. Chung, I. MacLaren and D. H. Gregory, CrystEngComm, 2015, 17, 5672.

41 Z. He, S. Yang, Y. Ju and C. Sun, J. Environ. Sci., 2009, 21, 268. 42 J. O. Carneiro, A. P. Samantilleke, P. Parpot, F. Fernandes, M. Pastor, A. Correia, E. A. Luís, A. A. Chivanga Barros and V. Teixeira, J. Nanomater., 2016, 4396175.

43 W. S. Rasband, ImageJ, U. S. National, Institutes of Health, Bethesda, Maryland, USA, 1997-2020, https:// imagej.nih.gov/ij/.

44 M. Leoni, T. Confente and P. Scardi, Z. Kristallogr. Suppl., 2006, 23, 249.

45 P. Scardi and M. Leoni, ECS Trans., 2009, 3, 125.

46 W. T. Sproull, X-Rays in Practice, McGraw-Hill, New York, 1946.

47 N. Serpone, D. Lawless and R. Khairutdinovt, J. Phys. Chem., 1995, 99, 16646.

48 N. D. Klein, K. R. Hurley, Z. V. Feng and C. L. Haynes, Anal. Chem., 2015, 87, 435.

49 D. B. Williams and C. B. Carter, Transmission Electron Microscopy, Springer, 2009.

50 T. Oshaka, F. Izumi and Y. Fujiki, J. Raman Spectrosc., 1978, 7, 321.

51 D. Bersani, P. P. Lottici and X.-Z. Ding, Appl. Phys. Lett., 1998, $72,73$.

52 M. N. Iliev, V. G. Hadjiev and A. P. Litvinchuk, Vib. Spectrosc., 2013, 64, 148.

53 A. Djerdj and A. M. Tonejc, J. Alloys Compd., 2006, 413, 159. 54 K. S. W. Sing, D. H. Everett, R. A. W. Haul, L. Moscou, R. A. Pierotti, J. Rouquérol and T. Siemieniewska, Pure Appl. Chem., 1985, 57, 603.

55 K. S. W. Sing and R. T. Williams, Adsorpt. Sci. Technol., 2004, 22, 773.

56 M. Thommes, K. Kaneko, A. V. Neimark, J. P. Olivier, F. Rodriguez-Reinoso, J. Rouquerol and K. S. W. Sing, Pure Appl. Chem., 2015, 87, 1051.

57 V. Etacheri, M. Seery, S. Hinder and S. Pillai, Inorg. Chem., 2012, 51, 7164. 
58 T. Bezrodna, G. Puchkovska, V. Shymanovska, J. Baran and H. Ratajcak, J. Mol. Struct., 2004, 700, 175.

59 R. Urlaub, U. Posset and R. Thull, J. Non-Cryst. Solids, 2000, 265, 276.

60 J. A. Navio, C. Cerillos and C. Real, Surf. Interface Anal., 1996, 24, 355.

61 Y. C. Zhang, M. Yang, G. Zhang and D. D. Dionysiou, Appl. Catal., B, 2013, 142-143, 249.

62 M. Mochida and B. J. Finlayson-Pitts, J. Phys. Chem. A, 2000, 104, 9705.

63 L. B. Xiong, J.-L. Bi, B. Yang and Y. Yu, J. Nanomater., 2012, 831524.

64 J. Park, T. Back, W. C. Mitchel, S. S. Kim, S. Elhamri, J. Boeckl, S. B. Fairchild, R. Naik and A. A. Voevodin, Sci. Rep., 2015, 5, 14374.

65 Y. G. Zhang, L. L. Ma, J. L. Li and Y. Yu, Environ. Sci. Technol., 2007, 41, 6264.

66 J. Li, L. Liu, Y. Yu, Y. Tang, H. Li and F. Du, Electrochem. Commun., 2004, 6, 940.

67 T. Jia, F. Fu, D. Yu, J. Cao and G. Su, Appl. Surf. Sci., 2018, 430, 438.

68 E. Ovodok, H. Maltanava, S. Poznyak, M. Ivanovskaya, A. Kudlash, N. Scharnagl and J. Tedim, Mater. Today: Proc., 2018, 5, 17422.

69 S. W. Koch, M. Kira, G. Khitrova and H. M. Gibbs, Nat. Mater., 2006, 5, 523.

70 L. E. Brus, J. Phys. Chem., 1986, 90, 2555-2560.

71 G. Cao and Y. Wang, Nanostructures and Nanomaterials: Synthesis, Properties and Applications, World Scientific, 2011.

72 J. Turkevic, Gold Bull., 1985, 18, 125.

73 S. Y. Chae, M. K. Park, S. K. Lee, T. Y. Kim, S. K. Kim and W. I. Lee, Chem. Mater., 2003, 15, 3326.

74 Evonik industries, AEROXIDE®, AERODISP ${ }^{\circledR}$ and AEROPERL ${ }^{\circledR}$ Titanium Dioxide as Photocatalyst, (Technical Information 1243).

75 F. Kanoufi, Y. Zu and A. J. Bard, J. Phys. Chem. B, 2001, 105, 210.

76 A. V. Deshpande and U. Kumar, J. Lumin., 2010, 130, 839.
77 W. K. Jo and R. J. Tayade, Chin. J. Catal., 2014, 35, 1781.

78 T. Watanabe, T. Takizawa and K. Honda, J. Phys. Chem., 1977, 81, 1845.

79 Y. Fan, G. Chen, D. Li, Y. Luo, N. Lock, A. P. Jensen, A. Mamakhel, J. Mi, S. B. Iversen, Q. Meng and B. B. Iversen, Int. J. Photoenergy, 2012, 173865.

80 S. Wahyuningsih, C. Purnawan, P. A. Kartikasari and N. Praistia, Chem. Pap., 2014, 68, 1248.

$81 \mathrm{X} . \mathrm{Hu}, \mathrm{T}$. Mohamood, W. Ma, C. Chen and J. Zhao, J. Phys. Chem. B, 2006, 110, 26012.

82 D. L. Thorn and W. C. Fultz, J. Phys. Chem., 1989, 93, 1234. 83 Z. Li, S. Cong and Y. Xu, ACS Catal., 2014, 4, 3273.

84 J. C. Yu, J. Yu, W. Ho and L. Zhang, Chem. Commun., 2001, 1942.

85 H. Zhao, L. Liu, J. M. Andino and Y. Li, J. Mater. Chem. A, 2013, 1, 8209.

86 X. Wang, S. Jin, H. An, X. Wang, Z. Feng and C. Li, J. Phys. Chem. C, 2015, 119, 22460.

87 A. Li, Z. Wang, H. Yin, S. Wang, P. Yan, B. Huang, X. Wang, R. Li, X. Zong, H. Han and C. Li, Chem. Sci., 2016, 7, 6076.

88 A. Di Paola, M. Bellardita, R. Ceccato, L. Palmisano and F. Parrino, J. Phys. Chem. C, 2009, 113, 15166.

89 L. Gai, X. Duan, H. Jiang, Q. Mei, G. Zhou, Y. Tiana and H. Liu, CrystEngComm, 2012, 14, 7662.

90 D. L. Liao, G. S. Wu and B. Q. Liao, Colloids Surf., A, 2009, 348, 270.

91 J. Zhao, H. Hidaka, A. Takamura, E. Pelizzetti and N. Serpone, Langmuir, 1993, 9, 1646.

92 N. O. Mchedlov-Petrossyan, N. A. Vodolazkaya and A. O. Doroshenko, J. Fluoresc., 2003, 13, 235.

93 K. Shen and M. A. Gondal, J. Saudi Chem. Soc., 2017, 21, S120.

94 O. Merka, V. Yarovyi, D. W. Bahnemann and M. Wark, J. Phys. Chem. C, 2011, 115, 8014.

95 F. Chen, J. Zhao and H. Hidaka, Int. J. Photoenergy, 2003, 5, 209.

96 M. Graetzel, Acc. Chem. Res., 2009, 42, 1788. 